\title{
Enhancers et Silencers
}

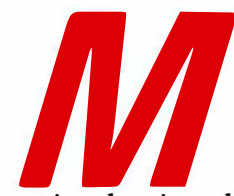

édecine/sciences expliquait récemment (glossaire $\left.d u n^{\circ} I, p . I I\right)$, ce qu'étaient les "enhancers "ou séquences stimulatrices de la transcription découvertes en I98I. Depuis la parution de cet article, un autre type d'élément régulateur de la transcription des gènes a été identifié: il s'agit des séquences extinctrices (ou inhibitrices) appelées "silencers" en anglais [I]. Comme leur nom l'indique, ces séquences agissent en maintenant silencieux des gènes qui doivent être réprimés.

Exactement comme les "enhancers", ces "silencers " sont actifs à distance des gènes (jusqu'à plusieurs milliers de base des promoteurs) en amont aussi bien qu'en aval d'eux et sont dépourvus de polarité, ce qui signifie qu'ils demeurent pleinement actifs lorsqu'ils sont excisés et réinsérés dans l'orientation opposée sur le double brin d'ADN. Comme dans le cas des "enhancers ", leur action, c'est-à-dire leur pouvoir de réprimer les gènes, dépend de la présence de facteurs diffusibles, probablement protéiques, qui pourraient se lier à eux, et ainsi les activer.

La différenciation cellulaire étant une suite d'activation de certains gènes et de répression d'autres, la découverte de ces séquences extinctrices et de leur régulation par des facteurs diffusibles " extincteurs " constitue probablement une pièce maîtresse de notre connaissance des divers éléments du contrôle de l'expression $d u$ génome.

A. $\mathbf{K}$.

\footnotetext{
1. Brand A H, Breeden L, Abraham J, Sternglanz M, Rand Nasmyth K. Characterization of a "Silencer" in yeast: a DNA sequence with properties opposite to those of a transcriptional enhancer. Cell I985; 4I: 4I-8.
}

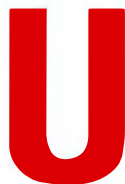

ne étude épidémiologique conduite par des auteurs canadiens aboutit à ce résultat surprenant: la mortalité par cirrhose est correlée de façon statistiquement très significative avec la consommation de viande de porc [1].

Les auteurs ont utilisé les données publiées concernant la consommation de graisses, de viande de porc, de viande de bouf et d'alcool pour l'année 1965 dans 16 pays. Ils ont calculé la corrélation entre consommation de ces substances et mortalité par cirrhose pour cette même année 65. Pour l'ensemble des 16 pays, une corrélation significative a été trouvée entre mortalité par cirrhose et consommation d'alcool, ce qui n'est pas surprenant, mais aussi entre mortalité par cirrhose et consommation de viande de porc, alors qu'aucune corrélation n'a été trouvée entre mortalité par cirrhose et consommation de bœuf ou de graisses. La corrélation la plus forte a été trouvée entre la mortalité par cirrhose et le produit de la consommation d'alcool par la consommation de viande de porc. Dans 7 pays ayant une consommation d'alcool voisine par habitant $(7,5$ à 11 litres par an) et une mortalité par cirrhose très différente (2 à 18 morts pour 100000 habitants), il n'y avait pas de corrélation entre mortalité par cirrhose et consommation d'alcool, mais une corrélation significative entre mortalité par cirrhose et consommation de porc. La même constatation a été faite dans 11 pays européens ayant une consommation d'alcool faible ( 5 à 10 litres par an par habitant), et dans 10 provinces canadiennes. Dans aucun des cas, il n'existait une corrélation significative entre viande de bœuf et morta- lité par cirrhose. Enfin, dans tous les pays étudiés, la prévalence du portage chronique du virus de l'hépatite B était inférieure à $1 \%$. La corrélation entre consommation de porc et mortalité par cirrhose est donc très significative selon cette étude, particulièrement dans les pays où la consommation d'alcool est faible. Cette corrélation n'est pas due à une infection par le virus $B$ (autre grande cause de cirrhose) car la prévalence du portage chronique du virus dans les pays examinés est faible (toujours inférieure à $1 \%$ ) et voisine d'un pays à l'autre.

A quoi est due cette corrélation? Schématiquement, on pourrait répondre qu'ou bien il existe une relation causale entre porc et cirrhose, ou bien la consommation de porc est étroitement liée à un autre facteur de l'environnement jouant un rôle dans l'apparition de la cirrhose (et distinct de l'alcool ou du virus de l'hépatite B). Rien ne permet de choisir entre ces deux possibilités. La seule différence notable entre la composition de la viande de bœuf et celle de porc est le contenu plus élevé de celle-ci en acide linoléique. Cette corrélation, si elle se confirmait, aurait des implications importantes. Il est bien connu, notamment, qu'à consommation d'alcool égale, le risque de cirrhose diffère grandement d'un individu à l'autre. Il faut donc postuler soit une prédisposition génétique, soit un facteur associé. Le porc pourrait-il être un tel facteur?

Finalement, nous faudra-t-il respecter les prescriptions diététiques que nous enseignent l'Islam et le judaïsme depuis des siècles? Attendons peut-être confirmation de cette stimulante étude pour répondre à la question.

S. E.

I. Nanji AA, French SW. Relationship between pork consumption and cirrhosis. Lancet 1985 ; i: 681-3. 